\title{
Identification and Analysis of Instrument Industry Cluster on the Territory of the Russian Federation
}

\author{
Babkin Alexander Vasilievich ${ }^{1}$ \& Kudryavtseva Tatiana Jurievna ${ }^{1}$ \\ ${ }^{1}$ St. Petersburg Polytechnic University, 29, Polytechnicheskaya street, 195251, St.Petersburg, Russia \\ Correspondence: Kudryavtseva Tatiana Jurievna, St. Petersburg Polytechnic University, 29, Polytechnicheskaya \\ street, 195251, St.Petersburg, Russia.
}

Received: October 4, 2014

Accepted: October 7, $2014 \quad$ Online Published: December 2, 2014

doi:10.5539/mas.v9n1p109

URL: http://dx.doi.org/10.5539/mas.v9n1p109

\begin{abstract}
In this paper the role of clusters in industrial policy of regions is regarded. The main approaches to the identification of industrial clusters have been analyzed and the reasoning of the use of these approaches' tools has been given by the example of the instrumentation industry cluster of Saint Petersburg. The results of the formation of the cluster structure of instrument industry by the types of economic activity have been presented. The structure of the instrument industry cluster has been analyzed. The results of the calculation of the cluster forces by the statistics of employment in the territory of Russia have been presented. The peculiarities of the structure of the Russian instrument industry cluster have been formulated and regions of its localization have been defined.
\end{abstract}

Keywords: cluster, the structure of the cluster, instrument industry, localization coefficient, Russia, cluster policy.

\section{Introduction}

At the moment under the conditions of the increasing global competition, which covers not only the traditional markets for goods, capitals, technology and labor force, but also the system of national management, support for innovation, human potential development, especially important is the question of the formation of a new system of management, providing for the establishment new principles and mechanisms of regional policies, focused on the identification and development of competitive advantages of a region in order to enhance its investment attractiveness, the development of innovative potential, creation new work places, increase of production together with the improving of its quality characteristics, which ultimately will enhance the national competitiveness and the growth of national welfare. In this regard, special attention is given to the cluster approach as a new way of seeing of the national economy (Babkin, A., Kudryavtseva, T., \& Utkina, S., 2013; Andreev, V., \& Naumova, E., 2012; Babkin, A., Kudryavtseva, T., \& Bakhmutskaya, A., 2011; Rodionov, D., \& Nikolova, L. V., \& Mokeeva, T. V., 2014; Porter, M., 2005).

In the economic theory, the concept of clusters was introduced by the American economist Michael Porter (Porter, M. (2003), (2005). Porter defines a cluster as a group of geographically adjacent interconnected companies and organizations related with them operating in a particular area and are characterized by common activities and are complementary to each other. In addition, Porter believes that geographical scale of a cluster can vary from one city or state to a country or even a number of neighboring countries.

The concept of long-term socio-economic development of the Russian Federation until 2020, provides for the creation of a network of territorial-industrial clusters, which realizes the competitive potential of the territories, the formation of a number of innovative high-tech clusters, including instrument industry, in the European and Asian parts of Russia (Russian Federation Government Decree \#1662-r from 17.11.2008). Under the instrument industry in this study a branch of science and technology is understood, which develops and manufactures measuring instruments, processing and reporting devices, automatic and automated control systems. An inseparable part of instrument industry is radio-electronics, because radio-electronic products define the intellectual abilities of all final goods instrument industry products, allows you to extend the functionality and the human habitat on earth and in outer space.

The purpose of this study is to determine the industrial structure of the Russian instrument industry cluster and 
places of its localization in Russia, i.e. geographical boundaries of the cluster.

\section{Methods}

The main methodological problem in the implementation of cluster policy is the identification of clusters (Babkin, A., Kudryavtseva, T., \& Bakhmutskaya, A. (2011); Vorobyov, V., \& Lipatnikov, V. (2012); Kovalev, T. (2011)). Having summarized the work of Russian and foreign researchers devoted to cluster analysis, we can distinguish two main approaches to identify clusters (Kutcenko, E. (2009); Caplin, A. (2013)): so-called the "bottom" according to which clusters are identified in a particular territory on the basis of the presence of well-known companies and industries leaders; the "top" approach, which involves the search of spatial localization of industries, oriented to specific economic activities.

For the implementation of the initial analysis within the second approach the types of economic activities are defined that have the effect of complementarity, the so-called "standard" clusters. As a result of numerous studies of M. Porter he fully succeeded to determine the structure of "standard" clusters based on a variety of activities, presented at the American qualifier SIC (Standard Industrial Classification). However, it should be noted that the concept of "standard" cluster even in the national economy is only a probabilistic indicator of economic agglomerations of related activities. At the same time, when you change the object of study, the composition and structure of the "standard" clusters may vary, reflecting the historical economic relationships unique to a given economy. Thus, in the project of the European Cluster Observatory for detecting and mapping of economic agglomerations across the European Union (European Cluster Observatory) the structure of "standard" clusters has been adapted to the European Union, taking into account the implementation of the European classifier NACE (Nomenclature Statistique des activités économiques dans la Communauté européenne).

Adaptation of foreign classifications of economic activities to the Russian analogue - GCEA (General Classification of Economic Activities) has not been carried out yet. Thus, under the current circumstances the only objective method for further cluster analysis in the Russian Federation will be a combination of two well-known approaches "from below" and "from above" to determine the structure of the "standard" cluster and the subsequent cluster analysis.

The "bottom" approach will be used in this study to identify the cluster groups in a particular area (federal district, the subject of the Federation), economic and historical development of which, as well as the presence of economic and innovative potential, revealed certain competitive industry leaders. Within this approach, the identification of cluster groups involves identifying of specific industries leading companies, specializing in the core activities, the so-called "core" of a cluster group, as well as the study of cooperation between 'core' enterprises of cluster group and other companies. In the cluster group can be included (Guidelines Ministry of Economic Development of the Russian Federation \#20615-ak / D19 of 26.12.2008, Babkin, A., Kudryavtseva, T., \& Utkina, S. (2013): companies that supply products or provide services to specialized companies; enterprise (organization), serving the public sector; organization of the market infrastructure; scientific-research and educational organizations; non-profit and non-governmental organizations, business associations, business houses; organization of innovation infrastructure and others. Defining enterprises that make up the cluster group will provide a set of activities for GCEA codes, which, in their turn, form a "standard" cluster. At the same time the quality of the main methods, used in this phase of the study can be described as: expert evaluations, interviewing, tools of theories of networks and graphs, SWOT and PEST-analysis (Kovaleva, T. (2011). The great importance has the study of the basic directions of state investment policy, the major federal programs and sectorial strategies.

Within the frame of the "top" approach it is supposed to use the created "standard" for the cluster analysis. In this case, cluster analysis is planned to be carried out in accordance with the methodology proposed by the European Cluster Observatory: so, according to statistics of employment cluster group is analyzed in terms of the coefficient of localization (1), size (2), focus (3).

$$
L Q=\frac{E_{m p_{i g}}}{E_{m p_{g}}} / \frac{E_{m p_{i}}}{E_{m p}}
$$

where LQ - localization coefficient of the cluster group $\mathrm{i} ; \mathrm{E}_{\mathrm{mp}} \mathrm{ig}_{\mathrm{g}}$ - number of employed in the cluster group i in the region $\mathrm{g} ; \mathrm{E}_{\mathrm{mp}_{\mathrm{g}}}$ - total quantity of employed in the region $\mathrm{g} ; \mathrm{E}_{\mathrm{mp}_{\mathrm{i}}}$ - quantity of employed in the cluster group i; Emp - total quantity of employed in all regions of the Russian Federation. 


$$
\text { Size }=\frac{E_{m p_{i g}}}{E_{m p_{i}}}
$$

where Size - size of the cluster group $\mathrm{i} ; \mathrm{E}_{\mathrm{mp}}$ - number of employed in the cluster group i in the region $\mathrm{g}$; $\mathrm{E}_{\mathrm{mp}_{\mathrm{i}}}$ - number of employed in the cluster group $\mathrm{i}$ in all regions of the Russian Federation.

$$
\text { Focus }=\frac{\mathrm{E}_{\mathrm{mp}} \mathrm{ig}}{\mathrm{E}_{\mathrm{mpg}}}
$$

where Focus - focus of the cluster group $\mathrm{i} ; \mathrm{E}_{\mathrm{mp}_{\mathrm{ig}}}$ - number of employed in the cluster group $\mathrm{i}$ in the region $\mathrm{g}$ $\mathrm{E}_{\mathrm{mp}}$ - number of employed in the region $\mathrm{g}$.

One of the researchers of the European Cluster Observatory - Swedish economist G. Lindqvist - established the criteria for these indicators evaluation (Lindqvist, G. (2009)) according to a localization coefficient $\geq 2$; according to size and focus indexes the region should be among the $10 \%$ of the regions, leading by these indicators.

Implementation of the limitation conditions for each indicator means assigning "stars" to a cluster group 1. Thus, one or another cluster can get 3 "stars" maximum.

It should be noted that the restriction by the index of "localization coefficient" to be applied within the frame of the study of the European territory, at the time, American researchers from the Harvard Business School (Cluster Project at Harvard Business School) limitation on the same indicator was stated otherwise: $\geq 1.3$. By their nature, the localization index characterizes the ununiformed distribution of population in a certain territory. It becomes apparent that the differences in the definition of the boundaries of the index are linked primarily with different geographical characteristics of Europe and America: for example, the average population density in Europe is 72 individuals $/ \mathrm{km}^{2}$, while in America is 32 individuals $/ \mathrm{km}^{2}$. In view of the large and relatively low population density, economic geography of Russia, where the population density is 8.2 persons $/ \mathrm{km}^{2}$ and it is more in line with America than Europe, so in view of the circumstance to apply the restriction in terms of localization of $\geq$ 1.3 is more objective.

Thus, in the process of a cluster analysis, "from below" approach reveals cluster "standards" which are typical of the studied area, which eliminates the need to use during the study assumption of similarity of Russian and American economies, the so-called 'mirror' adaptation of SIC and GCEA. In turn, using the "top" approach it is possible to make the following first, to check out the offered hypothesis about the strength of a given cluster group in a particular region by the number of assigned "stars", and secondly, to identify regions, in which the studied cluster is significant. The presence of common borders of these regions with the tested ones suggests the existence of inter-territorial clusters, an account of which allows us to conduct more effective regional policy.

\section{Results}

The described method of clusters identification "from above" was used for the determination of Russia`s regions, in which the enterprises of instrument making cluster were concentrated. The approach «from below» was used for the researching of regional clusters enterprises. As an illustration of the proposed integrated methodology of cluster analysis we may present the key excerpts from the results of the research instrument industry cluster of Saint Petersburg. Saint Petersburg was considered in this research as the referent cluster, because it has the most high level of concentration of instrument making enterprises comparing with the other regions of Russia.

There was assumed that there is a cluster group, the core of which is enterprises of radio-electronic industry, in St. Petersburg, because: (1) the concept of long-term socio-economic development of the Russian Federation for the period until 2020 and specialization of north-western region determines the development of traditional industrial sectors, including instrument industry (decree of the Government of the Russian Federation \#1662-p from 17.11.2008); (2) the state program "Development of electronic and radio-electronic industry for 2013-2025" defines a creation and development of organizations and projects that meet the key success factors in the priority areas, through an effective industry cluster strategy, including in St. Petersburg (decree of the Government of the Russian Federation \#2396-p from 15.12.2012); (3) The Committee on Industrial Policy and Innovation of St. Petersburg one of the 8 priority cluster of electronics is pointed out (Administration of St. Petersburg, 2014); (4) in St. Petersburg, in 2008 on the basis of the facilities of radio-electronic complex, the St. Petersburg Association of electronics, instrument industry, communications, and information and telecommunications is created (Association of electronics, instrument industry, communications, and information and telecommunications, 2014); (5) in St. Petersburg international industrial exhibition "Radio electronics. Instrument industry. Automation" is annually conducted (House of Commerce and Industry of the Russian Federation, 2014). All of this suggests the existence of economic and innovative potential of St. Petersburg City 
agglomeration in the field of instrument industry and electronics in particular.

In addition, of the great importance is the fact that the radio-electronic industry makes a significant contribution to the solution of the problem of GDP doubling in ten years, since products industry has a significant multiplier effect in adjacent fields (decree of the Government of the Russian Federation \#2396-p from 15.12.2012). In its turn, this fact suggests that the radio-electronic cluster highlighting and conducting state investment policies in its respect may have a synergistic effect on other sectors.

Applying the approach "from below" based on a study of industrial policy priorities of the federal and regional level, addressing the key sectorial targeted programs (including the Federal Target Program "Development of Electronic Component Base and Radio Electronics" in 2008-2015; Federal Target Program "Development of broadcasting in the Russian Federation in 2009-2015 years"), enterprises-participants of the association of the radio electronics, as well as their cooperative links, were pointed out 83 enterprises that make up not only the core of the cluster group, but also form the technical infrastructure of the cluster as a whole. The study of the NACE codes both, by the main and supplementary types of activities of the selected enterprises (Association of electronics, instrument industry, communications, and information and telecommunications, 2014), allowed to form the structure of the cluster.

In simplified form, the instrument industry cluster of Saint Petersburg is divided into three main blocks: the core of the cluster, business infrastructure and industrial infrastructure. The interconnection of the blocks a non-profit organization actually implements - the association of instrument industry and electronics cluster, which interrelates interests of cluster enterprises, branch federal and regional authorities, non-commercial and commercial organizations, serving the interests of the cluster. Business infrastructure implements financial and informational functions at both, federal and regional level. The industrial infrastructure is used for the effective cooperation of the cluster enterprises for the production of innovative high-quality products - radio-electronic systems that have both, military and civilian applications. Thus, the horizontal connections of the cluster are implemented within an industrial infrastructure, vertical - within business infrastructure. The main structural element of the industrial infrastructure of the instrument industry cluster of St. Petersburg is the core of the cluster - a set of enterprises that produce the main final products of the cluster and is the ultimate consumer of goods and services, produced and provided by other structural elements of the cluster.

The peculiarity of the tested cluster is the presence of "dual core" system: for example, the main core of the cluster are companies that produce radio-electronic systems for naval equipment, aviation and space, telecommunications; "Auxiliary" cluster core are enterprises producing "micro" systems - equipment, which is part of a large complex. This "dual-core" predetermined the following peculiarity: the main core enterprises, mainly working under the state order and are state-owned were created in 1920-1940-ies for the interests of the Russian Federation Ministry of Defense. The share of civilian products, manufactured at its own expense, rather than state funding, of these companies is less than 5\%. While the companies of the "auxiliary" core are more oriented to the market, have more opportunities to diversify their products, have a significant share of civilian products in its product portfolio. For them, the reduction in state funding as a way to ensure the activity is less significant risk than for the main core enterprises.

Production infrastructure of the instrument industry cluster of St. Petersburg provides the main activity of the cluster, which is manifested in the production of the final product - electronic systems for the Navy, space, aviation and telecommunications. Business infrastructure supports the development of primary activities: state investments provide technical re-equipment, and stimulate the growth of production, including innovation; SEZ (special economic zones) through the provision of rent, tax and customs benefits reduce the cost of enterprises; organization of information, legal support and advertising and exhibition activities by an organizing of various educational and exhibition arrangements to increase the number of horizontal connections of the cluster, facilitates the expansion of the zone of action, stimulates the export activity. Ultimately, the overall activity of the business-structure units leads to the increase in the competitiveness of products, the growth of output, resulting in economic growth at the regional level, the growth of the number of employees and increases the export turnover.

Fig. 1 shows the structure of the instrument industry cluster of St. Petersburg in the context of the industrial enterprises of various types of economic activities, included in the cluster. 


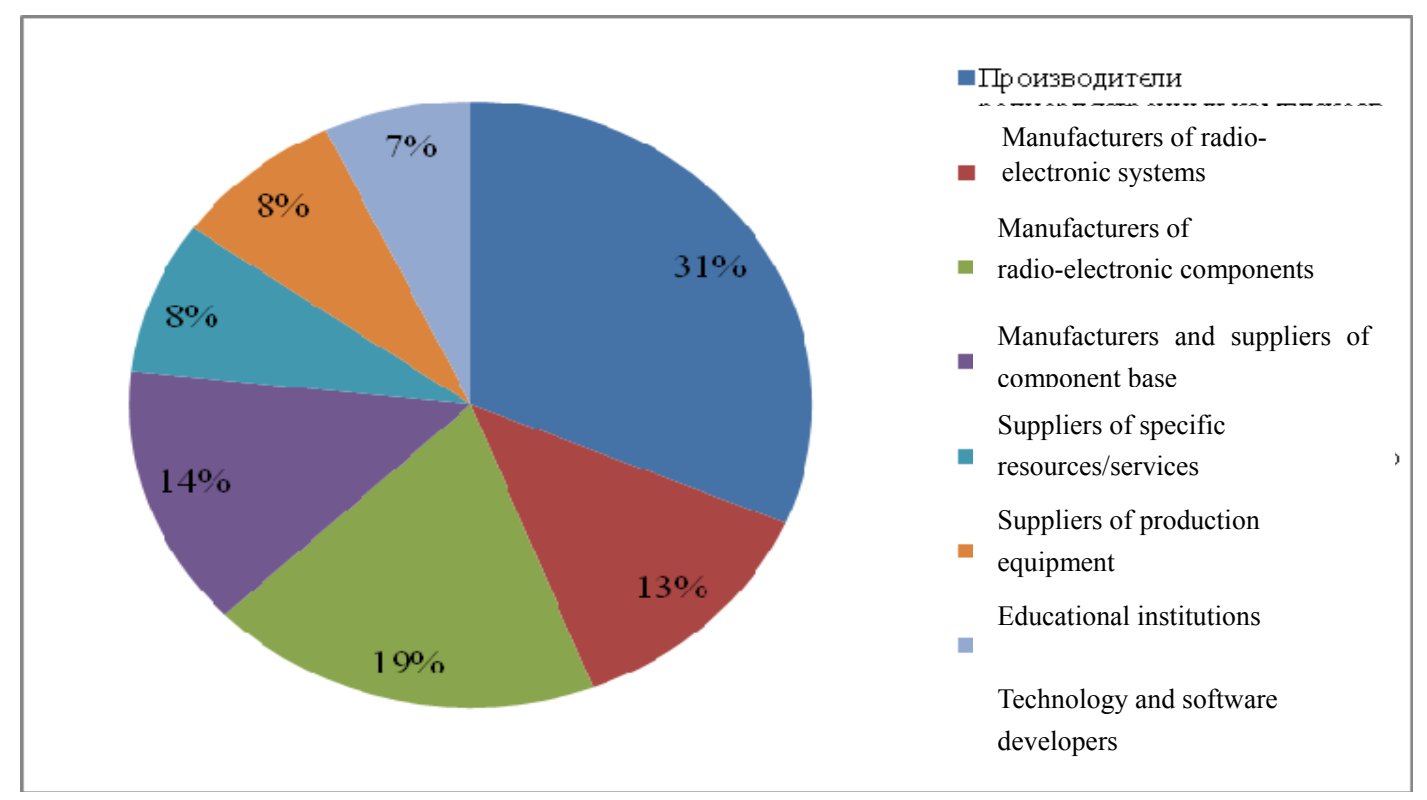

Figure 1. Share of enterprises by types of economic activity, comprising industrial infrastructure of instrument industry cluster of Saint Petersburg

As a result of analysis of the enterprises' activity of industrial infrastructure of instrument industry cluster in St. Petersburg the following conclusions were drawn:

- the largest group of companies is the core of the cluster - 44\%; of which: enterprise-producers of radio-electronic systems - 31\%; enterprise-producers of radio-electronic components - $13 \%$; enterprise-producers of radio-electronic systems for the most part, companies with $100 \%$ state-owned, and as a result of economic and historical reasons the given enterprises are integrated manufacturers of products that support all stages of development, production and marketing of products, so this group of horizontal communication with suppliers of specific services (electronics contract manufacturing) are weakened, which prevents more efficient growth of output and turnover;

$-19 \%$ of the total number of enterprises are manufacturers and suppliers of component base; however, it should be noted that less than half of them are manufacturers and the main part is Russian distributors of overseas component base;

$-14 \%$ of the companies are suppliers of specific resources/services of the cluster; this group of enterprises is the least homogeneous, because it includes both, enterprises, providing services for certified products and contract manufacturing as well as services for technical re-equipment of enterprises;

- small groups (8\%) - suppliers of production equipment and educational institutions; it should be noted that the suppliers of the production equipment, mainly Russian distributors of the German and Japanese equipment, many of them have significant regional network and have offices in St. Petersburg;

- the least numerous block - technology and software developers (7\%).

Comparison of the identified structure with the "Analytical Tools" cluster, formed by M. Porter on the basis of studies of the American economy (Porter, M. (2003)), is presented in Table 1. 
Table 1. The comparative analysis of the "Analytical instruments" and instrument industry clusters in Saint Petersburg

\begin{tabular}{|c|c|c|}
\hline \multirow[t]{2}{*}{ Analytical instruments (USA) } & \multicolumn{2}{|r|}{ Instrument industry (Russia) } \\
\hline & $\begin{array}{l}\text { NACE } \\
\text { codes }\end{array}$ & Types of activity \\
\hline \multicolumn{3}{|l|}{ Laboratory instruments } \\
\hline \multicolumn{3}{|l|}{ Optical instruments } \\
\hline \multicolumn{3}{|l|}{ Process equipment } \\
\hline Search and navigation equipment & 33.2 & Control devices production \\
\hline Electronic components & 32 & $\begin{array}{l}\text { Electronic components production, as well as } \\
\text { radio, television and connection equipment }\end{array}$ \\
\hline $\begin{array}{l}\text { Distribution and wholesaling } \\
\text { Electronic parts }\end{array}$ & 51.65 & Wholesale trade by other machines and equipment \\
\hline \multicolumn{3}{|l|}{ Other parts } \\
\hline \multicolumn{3}{|l|}{ Medical equipment } \\
\hline \multicolumn{3}{|l|}{ Related process equipment } \\
\hline \multicolumn{3}{|l|}{ Related equipment } \\
\hline Computer and software services & 72 & $\begin{array}{l}\text { Activity, connected with the use of computing } \\
\text { technology and informational technologies }\end{array}$ \\
\hline \multirow[t]{2}{*}{ Research organizations } & 73.1 & $\begin{array}{l}\text { Scientific researches and works in the field of } \\
\text { natural and technical science }\end{array}$ \\
\hline & 80.30 & The highest professional education \\
\hline
\end{tabular}

In general, the structures of the Russian and American clusters are similar. The main difference between the identified instrument industry clusters from the American analogue is the presence of the organizations in the structure of the cluster, which implement training and retraining of specialists - the "Higher education" activity type. In the American study, this type of activity is pointed out in a separate cluster. In addition, American cluster has a more detailed structure by type of activity. This is due, primarily, to the lack of competition in the Russian companies, producing electronic components, technological equipment, which indicates the high import dependence of the tested cluster and it is a major development issue.

It should also be noted that the vast majority of the investigated enterprises as the main type of activity have the "Scientific researches and works in the field of natural and technical sciences", while, core activity for the enterprises of instrument industry and radio-electronics by the type of products are "Production of control devices"," Manufacture of equipment for radio, television and communications". This semantic difference is due to the fact that the investigated enterprises are mainly engaged in technology-intensive industries, and to produce a new type of product researches and works are needed, as well as registration of patents and so on. This fact may also be connected with the matter that the largest enterprises in terms of number of employees and revenue are state-owned, and therefore, are active participants in the public procurement system, whereby the choice as the primary type of activity "Research and works in the natural and technical sciences" allows them to be more likely candidates for a major government contracts in terms of the transition to innovative development. In addition, among the majority of large enterprises the postgraduate training is organized; Dissertation Council on thesis for the degree of doctor and candidate of technical sciences takes place, scientific journals are issued, which publish the results of research and works of employees. This fact allows us to talk about the strong relationship between industrial enterprises and educational institutions.

The revealed cluster structure with a further cluster analysis was adopted as a "standard". Next, there were collected data by employment statistics of selected activities for all subjects of the Russian Federation for 2008-2012 (EMISS, 2014) and parameters on f. $(1,2,3)$ are calculated in order to identify the subjects of the Russian Federation, in which enterprises of instrument industry clusters are concentrated. The subjects, in which the analyzed cluster of instrument industry received more than 2 "stars", i.e. companies of investigated clusters are localized, focused and are of sufficient size for the number of employees in the region, are presented in Table 2. 
Table 2. The results of the instrument industry cluster analysis for the subjects of the Russian Federation

\begin{tabular}{|c|c|c|c|c|c|c|c|c|}
\hline & $\begin{array}{c}\text { Saint } \\
\text { Petersburg }\end{array}$ & $\begin{array}{c}\text { Moscow } \\
\text { region }\end{array}$ & Moscow & $\begin{array}{l}\text { Nizhny } \\
\text { Novgorod } \\
\text { region }\end{array}$ & Kaluga region & $\begin{array}{l}\text { Ryazan } \\
\text { region }\end{array}$ & $\begin{array}{l}\text { Penza } \\
\text { region }\end{array}$ & Tomsk region \\
\hline \multicolumn{9}{|c|}{2008} \\
\hline LQ & 2.21 & 1.34 & 2.15 & 1.33 & 1.63 & 1.31 & 1.34 & 1.50 \\
\hline Size & 0.0916 & 0.0616 & 0.2346 & 0.0374 & 0.0115 & 0.0101 & 0.0112 & 0.0108 \\
\hline Focus & 0.1141 & 0.0692 & 0.1113 & 0.0690 & 0.0841 & 0.0676 & 0.0693 & 0.0775 \\
\hline "Stars" & 3 & 3 & 3 & 3 & 2 & 2 & 2 & 2 \\
\hline \multicolumn{9}{|c|}{2009} \\
\hline LQ & 2.22 & 1.37 & 2.17 & 1.31 & 1.60 & 1.30 & 1.34 & 1.48 \\
\hline Size & 0.0945 & 0.0624 & 0.2336 & 0.0343 & 0.0114 & 0.0098 & 0.0114 & 0.0108 \\
\hline Focus & 0.1174 & 0.0724 & 0.1144 & 0.0690 & 0.0842 & 0.0687 & 0.0706 & 0.0780 \\
\hline "Stars" & 3 & 3 & 3 & 3 & 2 & 2 & 2 & \\
\hline \multicolumn{9}{|c|}{2010} \\
\hline LQ & 2.14 & 1.38 & 2.20 & 1.31 & 1.60 & 1.31 & 1.31 & 1.50 \\
\hline Size & 0.0919 & 0.0643 & 0.2373 & 0.0343 & 0.0114 & 0.0101 & 0.0113 & 0.0109 \\
\hline Focus & 0.1132 & 0.0733 & 0.1168 & 0.0693 & 0.0845 & 0.0696 & 0.0694 & 0.0794 \\
\hline "Stars" & 3 & 3 & 3 & 3 & 2 & 2 & 2 & 2 \\
\hline \multicolumn{9}{|c|}{2011} \\
\hline LQ & 2.20 & 1.46 & 2.22 & 1.33 & 1.55 & 1.33 & 1.29 & 1.54 \\
\hline Size & 0.0971 & 0.0657 & 0.2162 & 0.0354 & 0.0113 & 0.0104 & 0.0113 & 0.0112 \\
\hline Focus & 0.1172 & 0.0777 & 0.1184 & 0.0711 & 0.0827 & 0.0709 & 0.0688 & 0.0820 \\
\hline "Stars" & 3 & 3 & 3 & 3 & 2 & 2 & 1 & 2 \\
\hline \multicolumn{9}{|c|}{2012} \\
\hline LQ & 2.28 & 1.50 & 2.19 & 1.35 & 1.55 & 1.41 & 1.31 & 1.55 \\
\hline Size & 0.1011 & 0.0657 & 0.2160 & 0.0355 & 0.0116 & 0.0108 & 0.0114 & 0.0110 \\
\hline Focus & 0.1224 & 0.0802 & 0.1174 & 0.0725 & 0.0833 & 0.0754 & 0.0700 & 0.0829 \\
\hline "Stars" & 3 & 3 & 3 & 2 & 2 & 2 & 2 & 2 \\
\hline
\end{tabular}

In the figure 2 the cartogram is presented, which reflects the instrument industry cluster enterprises' distribution for the regions of the Russian Federation for 2012. As we can see, mainly, enterprises form the instrument industry meta-cluster in the Central Federal District.

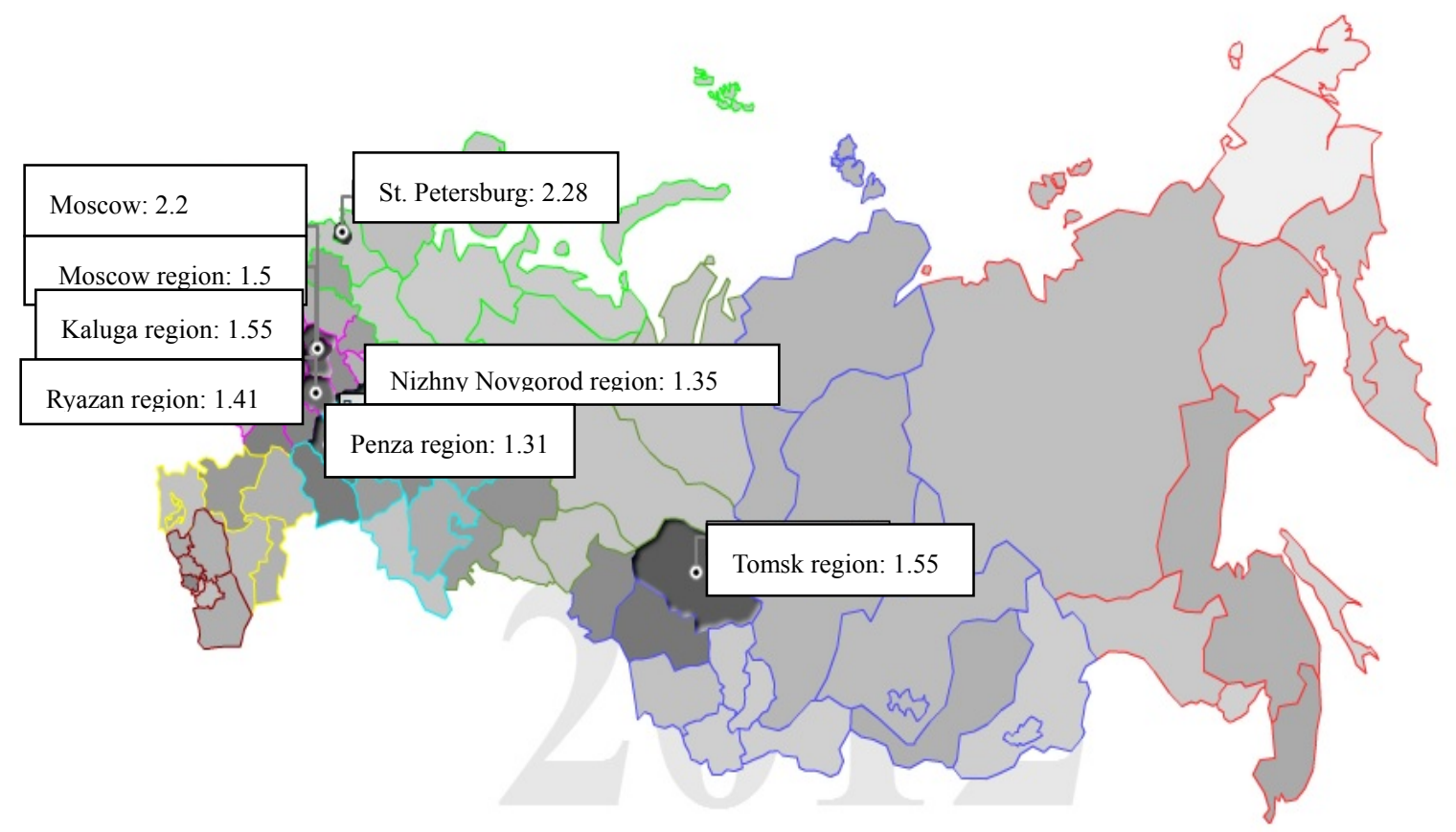

Figure 2. The localization of the instrument industry cluster enterprises by the regions of the Russian Federation of 2012. (after the name of the region the localization coefficient value is specified) 
As a result of the analysis of the localization of the instrument industry enterprises the following conclusions were drawn:

- instrument industry cluster is significant in the following subjects of the Russian Federation: St. Petersburg, Moscow region, Moscow, Nizhny Novgorod region, Kaluga Region, the Ryazan region, Penza region, Tomsk region;

- in the case of St. Petersburg, Nizhny Novgorod, Moscow, Kaluga, Tomsk regions it is connected with the historical economic specialization of the given subjects of the Russian Federation; in the case of Moscow and St. Petersburg, it is also associated with a considerable population of these cities because of their size and federal level (there is the highest rate of "localization" and "size" in these subjects); it should also be noted that Moscow, Moscow and Kaluga regions are included in the list of activities for the development of pilot innovative regional clusters, including in the field of instrument industry; in the Tomsk region there is a special economic zone of the implemental type;

- the instrument industry cluster in St. Petersburg is the most significant, even in relation to other important subjects of the Russian Federation: in St. Petersburg cluster instrument industry has a leading value by the localization and focus, which means that a significant portion of employed in St. Petersburg (more than 10\%) work in areas, related the instrument industry cluster; in addition, there is a positive trend in terms of localization, size and focus, which means that over the studied 5 years the power of instrument industry cluster in St. Petersburg increased.

\section{Discussion}

In the frame of the "bottom" approach, as a result of the qualitative analysis, the list of companies, included into the instrument industry cluster of Saint Petersburg was formed. Following the results of the study of the NACE codes by the main activities of enterprises and comparative analysis of the structure, offered by M. Porter, the cluster structure for the further analysis was formed, the so-called cluster "standard". In the frame of the "top" approach, within the use of the detected cluster "standard", the cluster analysis was carried out, using the methodology of the European Cluster Observatory for the subjects of the Russian Federation. Researching of structures of another regional clusters show that branch accessory of enterprises and their parity in the another regional clustera are similar. The most similar in the structure of the instrument making cluster of Saint Petersburg are the clusters of regions of Moscow, Moscow area, Tomsk area, Nizhny Novgorod area and Kaluga area. The main difference in the structure of clusters of Ryazyansk area and Penza area from accepted standard is the most higher share of enterprises, and the share reaches of $60 \%$ from the whole enterprises quantity of cluster, which is caused by the more lower indicators of urbanization of area and lower degree of enterprises variety.

On the whole, summing up the above analysis, the following conclusions are obtained:

- the main difference of detected cluster structure of instrument industry from the American analogue of the cluster of analytic tools - presence of educational institutions that provide training and retraining of specialists and lack of Russian companies, producing electronic components and technological equipment, which indicates the high import dependence of enterprises of cluster core and is the factor limiting development of cluster;

- by the employment statistics the investigated cluster group is localized in the North-West, Central, Privolzhky and Siberian federal districts; it should be noted that if the North-Western and Central and Privolzhsky federal districts have adjacent geographic boundaries, the Siberian Federal District is far enough; therefore, for development of intercluster bonds and, consequently, greater synergies effect transport links between the areas should be developed;

- in St. Petersburg the cluster of instrument industry has the highest indicators of localization and focus, for which there is a positive trend during the 5 years, taken under consideration, which means that a substantial part of employed in Petersburg (more than 10\%) work in areas, related to the cluster of instrument industry; in addition, there is a positive trend in terms of localization, size and focus, which means that during the studied 5 years the degree of localization of instrument industry cluster in St. Petersburg increased;

- the results, obtained in the frame of the cluster analysis are confirmed by the content of the federal cluster policy, reflected in the regulations, which indicates that the identified cluster structure can be cluster "standard", taking into account the peculiarities of the Russian Federation development.

\section{Conclusion}

Thus, according to the results of cluster analysis by the employment statistics there was confirmed the initial 
premise of a St. Petersburg instrument industry cluster, furthermore, in the process of work, it was determined that mainly in Saint Petersburg this cluster has the highest power. The article gives grounds for the use of tools of identification of regional industrial clusters by the example of instrument industry cluster. Thus, the application of the approach "from below" allowed formw cluster "standards", taking into account the peculiarities of the Russian economic development of instrument industry, and the "top" approach allowed to get statistical confirmations of the localization of the cluster groups in the regions of Russia. Novelty of the received results of research consists in structure definition of instrument making cluster of Russia and revealing of regions of localisation of the cluster enterprises in territory of Russia. This conclusion provides a basis for further, more detailed study of the instrument industry cluster: determining the perspectives of its development and foundation of activities of the regional cluster policy.

The article is prepared with the support of the Ministry of science and education of the Russian Federation (project No. 26.1303.2014/K).

\section{References}

Andreev, V., \& Naumova, E. (2012). Approaches to the estimation of regional clusters' functioning. Scientific technical journal of Saint Petersburg technical institute. Economical sciences, 4(151), 34-41.

Associations of radio electronics plants, instrument industry, connection devices and informational telecommunication (nd.). Retrieved September 22, 2012, from http://spbapr.ru/

Babkin, A., Kudryavtseva, T., \& Utkina, S. (2013). Identification and Analysis of Industrial Cluster Structure. World Applied Sciences Journal, 28(10), 1408-1413. Retrieved September 22, 2012, from www.idosi.org/wasj/wasj28(10)13/12.pdf

Babkin, A., Kudryavtceva, T., \& Bahmutskaya, A. (2011). Problems and directions of regional industrial politics formation (by the example of Saint Petersburg). News of Saint Petersburg state university of economics and finance, 4(70), 27-34.

Business House of the Russian Federation for the development of the subcontracting and clusters' technologies. $\begin{array}{llll}\text { Retrieved } \quad \text { September 22, 2012, from } & \text { 22 }\end{array}$ http://promcluster.ru/index.php/about-zak-cls/48-010-05-12-07-57-03.html

European Cluster Observatory. (nd.). Retrieved September 22, 2012, from www.clusterobservatory.eu/index.html

Kaplina, A. (2013). The analysis of the models of clusters structures formation in the system of regional economics: Managemental aspect. The Journal of Rostov State Institute of Economics, 4(44), 119-127.

Kovaleva, T. (2011). The algorithm of identification and estimation of clusters in the regional economics. The journal of Perm university, 4(11), 30-39.

Kutcenko, E. (2009). Clusters in economics. Detection practice. Scientific analytical journal Observer, 10(237), $109-126$.

Lindqvist, G. (2009). Disentangling Clusters. Agglomeration and Proximity Effects. Vällingby: Elanders.

Methodological recommendations for clusters' politics realization in the subjects of the Russian Federation \#20615-ак/д19. (2008, December 26). Confirmed by the MEDT of Russia.

Porter, M. (2003). The Economic Performance of Regions. Regional Studies. Carfax Publishing, 37(6/7), 549-578.

Porter, M. (2005). Competition. The translation from the English language. Moscow: The publishing house «Williams».

Rodionov, D., \& Nikolova, L.V., \& Mokeeva, T. V. (2014). The formation of the conflicts management models of the strategic alliances under the conditions of the globalization. Asian Social Science, 10(19), 296-302.

Saint Petersburg Administration. (n./d.). Saint Petersburg industrial politics and innovation committee. Retrieved September 22, 2012, from http://gov.spb.ru/gov/otrasl/c_industrial/klaster-radioelektroniki/

The cluster project of the Harvard business school. (n./d.). Retrieved September 22, 2012, from http://www.clustermapping.us

The instruction of the RF Government "About the conformation of long-term social economic development of the Russian Federation during the period till 2020" \#1662-p. (2008, November 17).

The instruction of the RF Government "About the conformation of the state program of the Russian Federation «Development of electronics and radio electronics industry in 2013-2025” \#2396-p. (2012, December 15). 
Unified interdepartmental informational statistical system (UIISS). (n./d.). Retrieved September 22, 2012, from http://www.gks.ru/wps/wcm/connect/rosstat_main/rosstat/ru/statistics/databases/emiss/

Vorobyev, V., \& Lipatnikov, V. (2012). Organizational principles of innovation industrial clusters formation. Scientific technical journal of Saint Petersburg technical institute. Economical sciences, 6(161), 63-70.

\section{Copyrights}

Copyright for this article is retained by the author(s), with first publication rights granted to the journal.

This is an open-access article distributed under the terms and conditions of the Creative Commons Attribution license (http://creativecommons.org/licenses/by/3.0/). 